ISSN 1112-9867

Available online at $\quad$ http://www.jfas.info

\title{
PREVALENCE AND FACTORS CONTRIBUTING TO MUSCULOSKELETAL DISORDER AMONG GARAGE WORKER IN MALAYSIA
}

\author{
A. Shukriah*, M. D. Baba, A. G. Jaharah \\ Faculty of Engineering \& Built Environment, Universiti Kebangsaan Malaysia, 43600, Bangi, \\ Selangor
}

Published online: 17 October 2017

\begin{abstract}
Maintenance involves task that is performed occasionally with exceptional conditions. This paper focused on Musculoskeletal Disorder (MSDs) among garage worker. The objective is to analyze the prevalence of Musculoskeletal symptoms among garage workers as well as the risk factors that contributed to the symptoms. Method used in this study is standard Nordic questionnaire (SNQ) Malay version for 150 garage workers who performed maintenance work on vehicle. The result of biomechanical evaluation indicated that three risk namely psychological, ergonomic and demographic play important role in contributing to MSDs. Shoulder, neck, wrist/hand, feet, low back and waist were among the body parts that recorded high percentage of developing bellow, pain and discomfort. Data gaps include lack of information regarding the prevalence of MSDs in garage worker
\end{abstract}

Keywords: vehicle maintenance; musculoskeletal disorder; ache, pain, discomfort; prevalence.

Author Correspondence, e-mail: shuk.kye@gmail.com

doi: http://dx.doi.org/10.4314/jfas.v9i5s.73 


\section{INTRODUCTION}

\subsection{Introduction}

According to Bureau of Labor Statistics, the overall affair of industrial machinery mechanics and garage workers is projected to grow 17 percent from 2012 to 2022 , promptly than the average for other employment. To manage the risk, garage workers should carefully take into account the risks when constructing their work environment. Garage worker or vehicle maintenance worker encountered certain MSDs risk, such as work posture and movement, manual labor and more. Minimal research was found on garage workers, however maintenance worker is considered as a comparison in most of MSDs research.

\subsection{Vehicle maintenance industry}

Vehicle maintenance workers have commitment to safety that gives trait related to their work engagement and attention. Industrial maintenance personnel maintain, install and dismantle, repair, monitor and troubleshoot equipment's or machinery used in the production of goods [1]. Considering the variability of activities in this industry, it is possible to feature tasks involving manual material handling. In the recent types of work, the extents of maintenance activities are boundless. These can range from conservative to the latest techniques of optimizing the maintenance role. Since the involvement of non-routine tasks which is not performed often, all the hazards associated with the job can be easily overlooked and as the result of the risk maintenance associated with all kinds of accidents. Within the Health Safety Executive, 2014/15 showed an estimated of 553,000 workers suffer from a Musculoskeletal disorder caused by their current or past work. Due to the lack of knowledge available in the literature regarding MSDs in maintenance industry, the purpose of this study was to evaluate Musculoskeletal symptom and work-related Musculoskeletal disorder among garage workers that also considering their social factors and individual thought and behavior. Most engineering and maintenance work activities are complicated and non-routine. The aim of this paper was to address the prevalence of Musculoskeletal disorder; which MSDs are likely to be associated with maintenance work. This type of Musculoskeletal disorder cover a wide range of body parts such as the back, upper limb and lower limb. Activities involving these body parts are most likely will develop the MSDs. 


\section{RESULTS AND DISCUSSION}

A Nordic questionnaire was distributed to detect pain and discomfort and it used Yes/No questions regarding the body parts and concerning of different time period, 'anytime' 'seven days' and ' 12 months' of work. The Likert scale consists of 5 points from 'strongly disagree' to 'strongly agree' in job content parts which describe the risk factors comprising psychological demand, decision latitude and workplace social support. Lastly, the result from each vehicle for all 50 garage workers is compare to find the differences of each type vehicle associate with MSDs.

\subsection{Demographic data}

The majority of the workers in this type of industry are male, age in between 18-60 years old with normal weight. Regarding their level of education, mostly have skill certificate from local institute. Their daily work lasting around or more than 8 hours per day and mostly they are a smoker. Their frequent postures while working are kneeling, bending, and several awkward postures.

\subsection{Prevalent and pattern related to MSDs}

Prevalence of shoulder for 12 months of period was 86 percent for those maintaining car and 92 percent from those maintaining bus. While for multi-purpose vehicle the prevalence result of the neck was 96 percent. Fig. 1 until Fig. 3 summarize the three time periods that is under study.

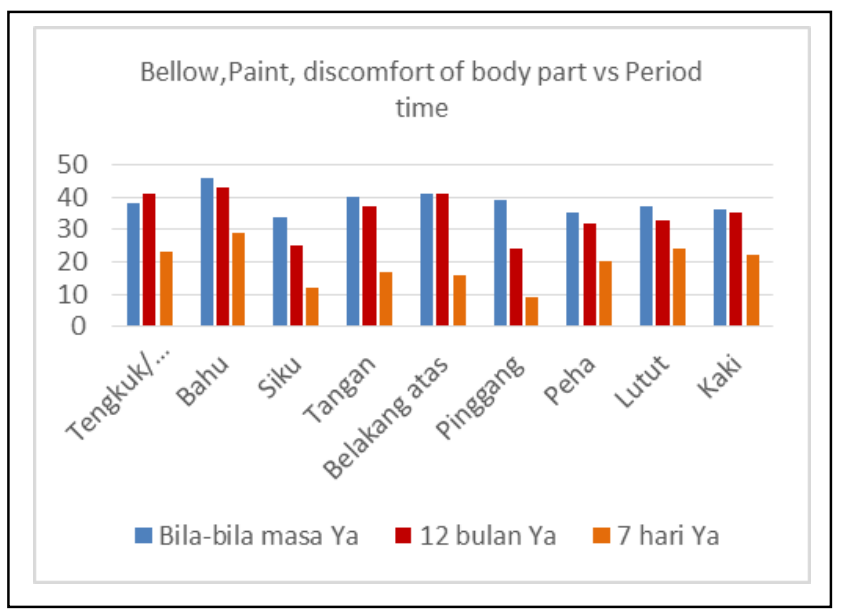

Fig.1. Prevalence of MSDs vehicle type: Car 


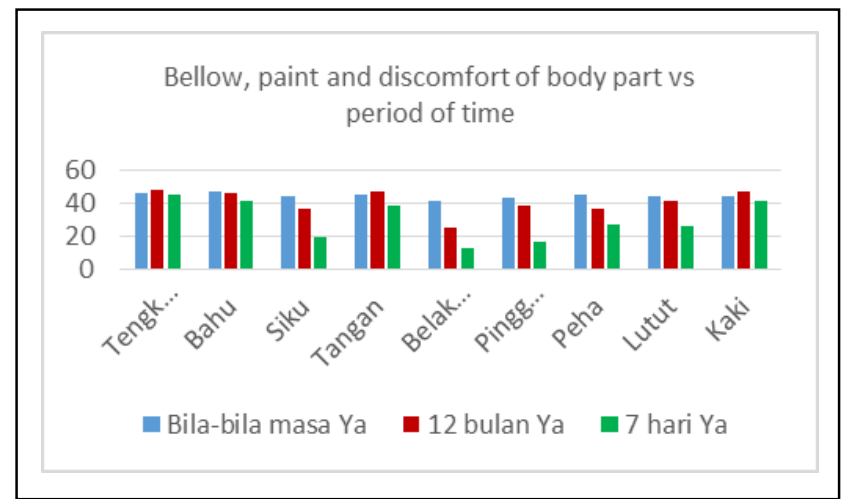

Fig.2. Prevalence of MSDs vehicle type: Multi-purpose

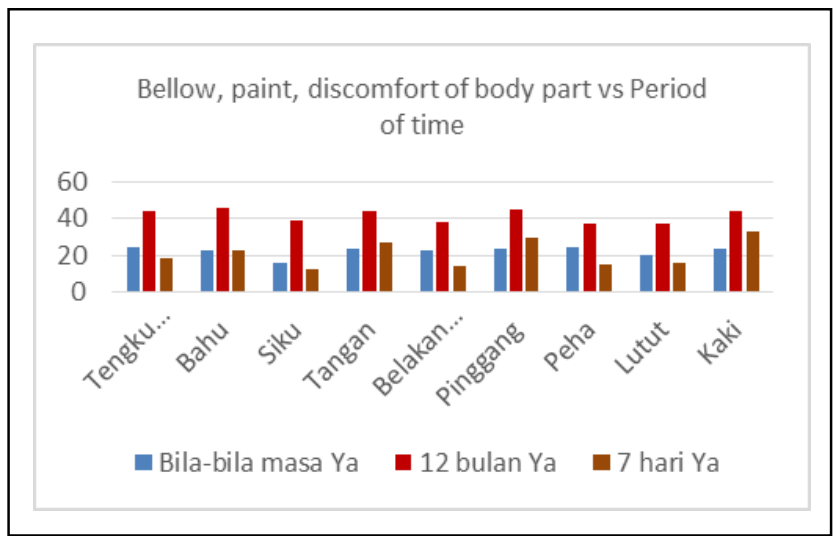

Fig.3. Prevalence of MSDs vehicle type: Bus

Result from personal interviews discovers new part to be studied. Most of the garage workers complained about headache while performing proper diagnosis on a vehicle. In addition most of car garage worker addressed their concern on lower back, while multi-purpose vehicle and bus workers stated waist as the body part that gave them much concern.

\subsection{Reliability questionnaire score}

The questionnaires on job content presented good internal reliability. This internal consistency associated with the score that derived from the scale. This Cronbach's Alpha helped determine whether it is justifiable to interpret score that has been aggregated together. The alpha coefficient for the 39 items are .868 for vehicle type car, .774 for vehicle type multipurpose and .891 for vehicle type bus.

The standard that makes good alpha coefficient is arbitrary on the theoretical knowledge of the scale in the questions. As for this study, a minimum alpha coefficient between 0.65 and 
0.8 are reliable set of items without need to decrease the number of items in the analysis. The 39 items are related to decision latitude, psychological demand, social support in the workplace, job demand and job insecurity. Mean computation in SPSS is use to determine the value of each answer from the questions. As presented in the Table 1 below; the length of the scale consisting 5 Likert's scale from 'strongly disagree' to 'strongly agree'. Most of the workers agree with the statement regarding their Job content while others think it is neutral. However mean are measures of central tendency, and standard deviation used to tell how well the values reflect to the studied data as referred to Table 2. This is important to test the statistical significance of the differences between the mean values.

Table 1. Mean score of each category in Job content

\begin{tabular}{cccc}
\hline & \multicolumn{3}{c}{ Type of Vehicle } \\
Categories & Car & MPV & Bus \\
\hline $\begin{array}{c}\text { Decision latitude } \\
\text { Psychological }\end{array}$ & 3.80 & 3.86 & 4.03 \\
$\quad$ demand & & 3.24 & 3.19 \\
$\begin{array}{c}\text { Social support in } \\
\text { workplace }\end{array}$ & 3.97 & 3.86 & 4.05 \\
$\quad$ & & \\
Job demand & 3.82 & 4.14 & 3.93 \\
Job insecurity & 3.70 & 3.50 & 3.33 \\
\hline \multicolumn{2}{l}{ Please use this paragraph to type the table footer(s) if any. }
\end{tabular}

Basically a small standard deviation means the values in a statistical data set are close to the mean of the data set showing how concentrate the data around the mean value. Large standard deviation reflected a large amount of variation in the group that is being studied. In this study, the data set has a really low standard deviation, it tells that the data is very close to each other and does not have huge outliers. 
Table 2. Standard deviation score

Type of Vehicle

\begin{tabular}{llrc} 
Categories & Car & MPV & Bus \\
\hline Decision latitude & .39847 & .35153 & .51247 \\
$\begin{array}{l}\text { Psychological } \\
\text { demand }\end{array}$ & .44028 & .38649 & .29443 \\
$\begin{array}{l}\text { Social support in } \\
\text { workplace }\end{array}$ & .56055 & .32397 & .66561 \\
$\begin{array}{l}\text { Job demand } \\
\text { Job insecurity }\end{array}$ & .36640 & .56508 & .56645 \\
\hline
\end{tabular}

\subsection{Contribute Factors}

Ergonomic risk factors discovered from another research regarding MSDs are being extracted to Pareto chart as shown in Fig. 4. Several other workplace ergonomic risk factors that is identified were material handling, handle different object, repetitive, short cycle operation, awkward posture and motion, forceful exertion, static posture, long working hour and vibration. These ergonomic risk factors are listed in Fig. 5. Systematic recognizing and controlling ergonomic risk factors is important to prevent MSDs and to provide a safe workplace for all the workers. There are vast literatures that demonstrated the risk that develops MSDs presented in ergonomic risk [1][2][3][4][5][6].

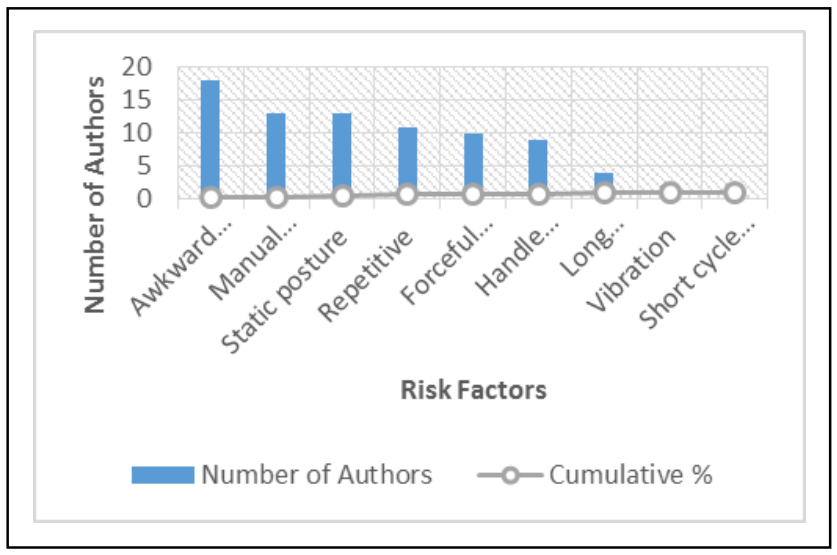

Fig.4. Review of another research regarding Ergonomic risk factor 


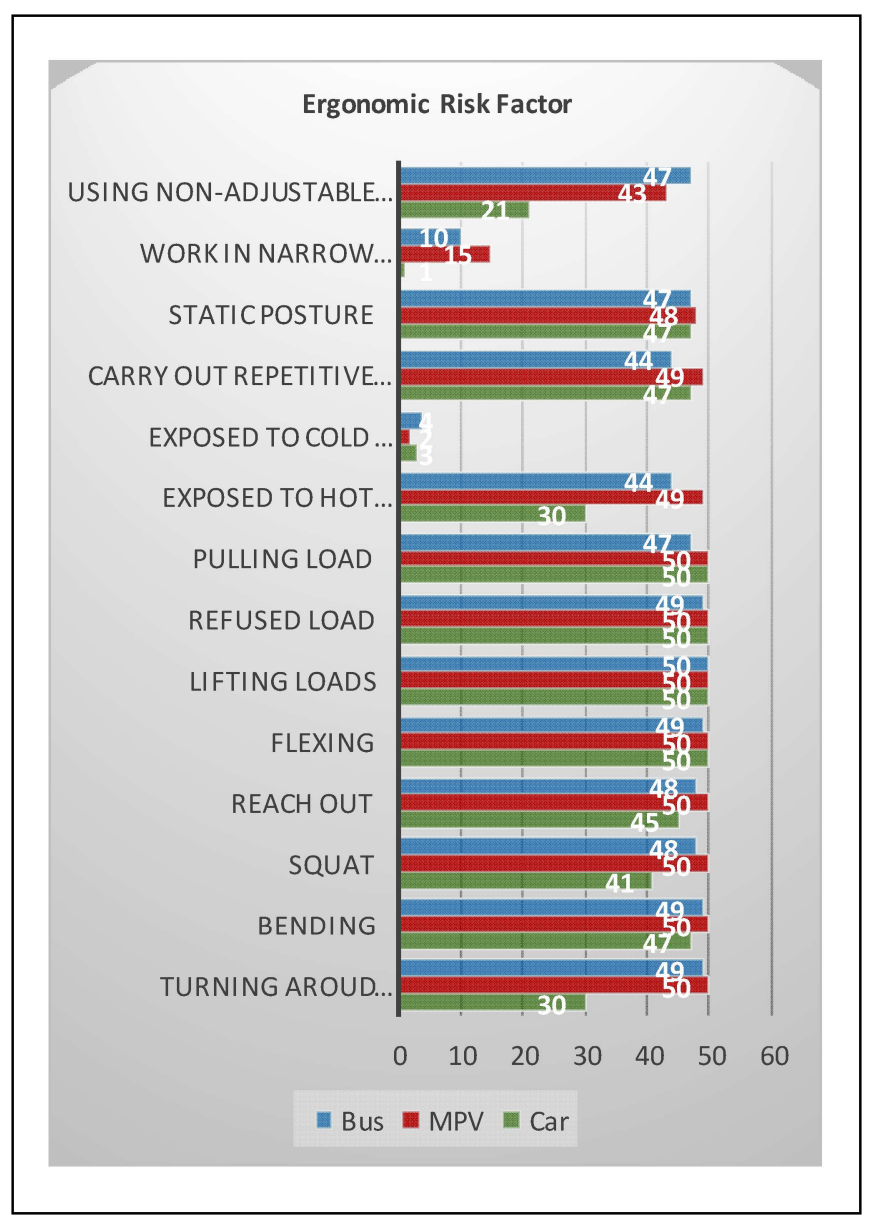

Fig.5. Ergonomic risk factors from the study

\subsubsection{The impact of Psychosocial and psychological}

Psychological risk factor is discussed on the engagement in the work. Psychological condition of a person depends on various factors, such as the impact of psychosocial conditions, psychosocial demand associated with stress, fatigue, and self-rated health. [7] did a psychosocial work on maintenance worker found that from eighty workers under studied, thirty workers were more engaged in their work, identified as symptomatic showed positive results as the same profile of demand and control of the asymptomatic workers. This is interesting as the presence of biomechanical risk factor should indicate the workers that are more involved in their work should be more exposed to risk factor that contributed to musculoskeletal symptoms. Most workers that have affected body region are those that have active work demand profile and high work engagement level. Although psychosocial factors were found significant in all types of MSDs, the neck and shoulder region showed more 
impact [8]. [9] Used two different cycle time in their study. They found out that lower cycle time contributed to high percentage on high psychological demands, but low percentages on decision latitude and job strain.

\section{METHOD}

\subsection{Method of survey}

This study used Nordic Musculoskeletal Questionnaire (NMQ) to assess the prevalence of bellow, pain and discomfort of human body parts. General information such as age, weight, level of education, and smoking habit are asked. Furthermore information on Work information such as working period, and Job content are also asked. The questionnaires are transformed into a Malay version to ease the understanding of the respondents.

A study with interval from 'anytime', 'seven days', and '12 months' working period were conducted to enable the analysis of prevalence and pattern that lead to pain and discomfort of the garage workers while performing their daily maintenance task. Workers from different garage are selected involving three types of vehicles. The study is conducted by distributing questionnaires and interviewing process. The interviewing and answering questionnaires are done during the workers rest periods, and been closely observe by the researcher to avoid misunderstanding and bias answering. Criteria for exclusion were if the participants had previous injury or an incident that happened outside their workplace whether at home, while exercising, or on the road that had cause bone fracture/ tendon, ligament, joint and muscle torn. The sample sizes were 150 workers, answering 100 percent of the questionnaires and none of them refused to give cooperation. The data are analyzed using SPSS software and Microsoft excel.

\section{CONCLUSION}

The prevalence of MSDs on garage workers who work on three types of vehicle showed different body parts felt bellow, pain and discomfort. The outcome of the interview conducted found out that majority of the garage workers felt bellow, pain and discomfort on the body part while performing their job. It can be summarized that garage worker that maintain car complained more about their low back while garage worker that maintain MPV and bus 
complained more about their waist. In addition headache is also being reported as a type of pain occurred while inspecting vehicles. The occurrence of headache among the garage workers was around 2-3 times per week. Finally only a few research papers regarding MSD and garage worker were found and there is insufficient information about this matters. This area of study can be expand more since garage workers are among those with high risk involving awkward posture and issues such as measurement tools and diagnostic criteria can be study in the future.

\section{REFERENCES}

[1] Bevilacqua M, CiarapicanF E, and Giacchetta G. Critical chain and risk analysis applied to high-risk industry maintenance: A case study. International Journal of Project Management, 2009, 27(4):419-432

[2] Nadeau S, Gagnon M. Work and energy transfers in maximal pushing of loads. International Journal of Industrial Ergonomics, 1996, 17(3):221-234

[3] da Costa B R, Vieira E R. Risk factors for work-related musculoskeletal disorders: A systematic review of recent longitudinal studies. American Journal of Industrial Medicine, 2010, 53(3):285-323

[4] Spallek M, Kuhn W, Uibel S, van Mark A, and Quarcoo D. Work-related musculoskeletal disorders in the automotive industry due to repetitive work-implication for rehabilitation. Journal of Occupational Medicine and Toxicology, 2010, 5(6):1-6

[5] Pollard J, Heberger J G, and Dempsey, P. Maintenance and repair injuries in US mining. Journal of Quality in Maintenance Engineering, 2014, 20(1):20-31

[6] Valero E, Sivanathan A, Bosché F, and Abdel-Wahab M. Musculoskeletal disorders in construction: A review and a novel system for activity tracking with body area network. Applied Ergonomics, 2016, 54, 120-130

[7] Oliveira A, Nogueira H, Diniz A, and Barbieri D. Psychosocial indicators among aircraft maintenance workers with and without neck and shoulder musculoskeletal symptoms. Work, 2012, 41(1): 5699-5701

[8] Crawford J O, Laiou E, Spurgeon A and McMillan G. Musculoskeletal disorders within the telecommunications sector: A Systematic Review. International Journal of Industrial 
Ergonomics, 2008, 38(1):56-72

[9] Zare M, Bodin J, Cercier E, Brunet R and Roquelaure Y. Evaluation of ergonomic approach and musculoskeletal disorders in two different organizations in a truck assembly plant. International Journal of Industrial, 2015, 50, 34-42

\section{How to cite this article:}

Shukriah A, Baba M D, Jaharah A G. Prevalence and factors contributed to musculoskeletal disorder among garage worker in Malaysia. J. Fundam. Appl. Sci., 2017, 9(5S), 1070-1079. 